\title{
Splenic Infarction in a COVID-19 Patient without Respiratory Symptoms
}

\author{
Shaikha Al Suwaidi Baidaa Jasem Alakasheh Labib S. Al-Ozaibi \\ General Surgery Department, Rashid Hospital, Dubai Health Authority, Dubai, UAE
}

\section{Keywords}

Coronavirus disease 2019 · Thromboembolism · Splenic infarction · Anticoagulants

\begin{abstract}
High rates of thromboembolic events have been seen in cases of COVID-19. Here, we report a case of 23-year-old previously healthy female presented with left-sided abdominal pain associated with vomiting. The computed tomography scan showed multiple ill-defined wedge-shaped low attenuating areas of the spleen, suggesting splenic infarction. In the absence of other thromboembolic contributing factors, we believe this was a thromboembolic event in splenic circulation in relation to COVID-19 infection. Our case adds to the evidence of an arterial thrombotic event in a noncritical COVID-19 patient, emphasizing the importance of addressing thromboembolism diagnosis and management measures to avoid potentially deadly consequences.

(c) 2022 The Author(s).

Published by S. Karger AG, Basel
\end{abstract}

\section{Introduction}

The coronavirus disease pandemic is a viral illness caused by severe acute respiratory syndrome coronavirus 2 (SARS-CoV-2), manifesting as an asymptomatic or mild-symptom to severe pneumonia [1,2]. Multiple studies and reports have linked the disease to a thromboembolic event, probably driven by distinct but as yet uncertain processes [3]. Although pulmonary embolism has been the most common thrombotic complication, there have been recent reports of COVID-19-associated largevessel ischemic events such as stroke, acute upper and lower limb ischemia, as well as infarction of the abdominal viscera, including renal, splenic, and small-bowel infarctions [4].

To the best of our knowledge, cases of splenic infarction associated with SARS-CoV-2 infection are rare in the literature. Here, we are reporting a case of splenic infarction in a 23-year-old COVID-19 patient.

\section{Case Presentation}

A 23-year-old previously healthy female came to the emergency department complaining of 1-day history of generalized abdominal pain, radiating to the back. The pain was relieved by sitting and worsened on lying flat. It was associated with 20 episodes of vomiting. Patient denied any respiratory symptoms or change in bowel or urine habits.

On examination, she was alert, oriented, and afebrile. The abdomen was soft, with tenderness on deep palpation on the left side of the abdomen (mainly the flank area). The patient was not in acute distress, her respiratory rate was 19, and oxygen saturation was $100 \%$. The lungs were clear on auscultation. The rest of systemic examination was normal. karger@karger.com www.karger.com/dmj

Karger $\stackrel{\text { ' }}{=}$

BOPEN ACCESS
(C) 2022 The Author(s)

Published by S. Karger AG, Basel

This is an Open Access article licensed under the Creative Commons Attribution-NonCommercial-4.0 International License (CC BY-NC) (http://www.karger.com/Services/OpenAccessLicense), applicable to the online version of the article only. Usage and distribution for commercial purposes requires written permission.
Correspondence to:

Baidaa Jasem Alakasheh, b.alakasheh@gmail.com 
Fig. 1. Abdominal CT scan, coronal view, showing the low attenuating area involving the lower half of the spleen.

Fig. 2. Abdominal CT scan, axial view, showing the low attenuating area of the lower spleen.
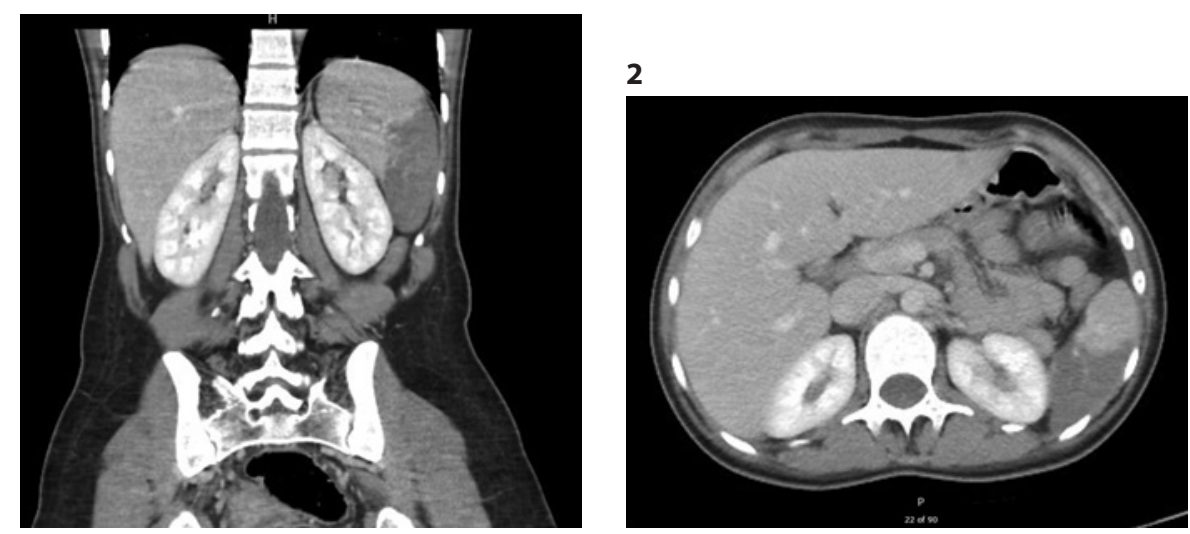

Investigations revealed an elevated white cell count of 17.7 with neutrophilia (15.3). She had an elevation in D-dimer of $1.54 \mathrm{ug} / \mathrm{mL}$ FEU (normal: $<0.5 \mathrm{ug} / \mathrm{mL}$ FEU). Amylase, lipase, liver, and renal function tests were all within normal limits.

On admission, the SARS-CoV-2 test was done routinely as per the hospital's protocol and came out positive. Computed tomography of the abdomen with IV contrast was done and showed a mildly enlarged spleen with multiple ill-defined wedge-shaped low attenuating areas, involving the entire left lower half, consistent with splenic infarction (Fig. 1, 2).

Blood tests were done to exclude other causes of coagulopathy. Anti-double-stranded DNA, anticardiolipin, antinuclear antibody, anti-beta-2-glycoprotein, complement C3, complement C4, and extractable nuclear antigen profiles were all normal.

The patient was diagnosed with splenic infarction due to coagulopathy caused by SARS-CoV-2 infection. She was started on rivaroxaban $(20 \mathrm{mg})$. The patient was kept on conservative management, and her condition improved.

\section{Discussion}

Patients with COVID-19 pneumonia may be predisposed to thrombotic complications due to excess inflammatory response, endothelial dysfunction, platelet activation, and stasis of blood flow [5]. Rates of thrombotic complications may be as high as $31 \%$ in patients with COVID- 19 . For that reason, current guidance statements recommend the use of standard-dose thromboprophylaxis with unfractionated heparin or low-molecular-weight heparin which reduced the incidence by one-half to two-thirds [6].

However, the adequacy of standard thromboprophylaxis is challenged by emerging studies reporting a high incidence of venous thromboembolism (VTE) among anticoagulated patients. A report from France revealed that compared to the matched historic non-COVID-19 cohort, COVID-19 patients with acute respiratory distress syndrome had a 5 -fold risk of pulmonary embolism despite anticoagulation (11.7\% vs. $2.1 \%)$ [7].
Based on aggregate data from cohort studies, $24 \%$ of COVID-19 patients who received thromboprophylaxis developed VTE [8]. Some COVID-19 infection cases has been associated with abnormalities in coagulation parameters (e.g., D-dimer, prothrombin time, partial thromboplastin time, fibrin/fibrinogen degradation products, and platelet counts) that are consistent with infection-induced inflammatory changes as observed in disseminated intravascular coagulopathy [9]. Guidelines suggest monitoring $\mathrm{D}$-dimer, fibrinogen, prothrombin time, and platelet count to determine prognosis and assist management decision in COVID-19 patients requiring hospitalization [10]. Deterioration of coagulation parameters may warrant more aggressive critical care support.

Although the most common pattern of coagulopathy observed in patients hospitalized with COVID-19 is characterized by elevations in fibrinogen and D-dimer levels and mild prolongation of PT/aPTT [11], some previous studies showed that the coagulopathy in patients hospitalized with COVID-19 is characterized by increase in INR too. A prospective cross-sectional study was conducted among 455 COVID-19 patients admitted at the COVID-19 care and treatment center, Ethiopia, from July 1 to October 23, 2020, which showed that prolonged INR was more frequent among severe and critical COVID-19 patients [12].

Although rare in the literature, cases of an acute abdomen in COVID-19 patients associated with vascular infarctions of the abdominal viscera, including renal, splenic, and small bowel, have increased. Some cases of COVID-19 patients with respiratory symptoms coming with splenic infarction were reported.

Castro et al. [13] reported a case about splenic infarction presented in a COVID-19 patient without any clinical respiratory manifestations of the disease as the patient 
presented in our case. This kind of presentation is rare in the literature.

Splenic infarction occurs when blood flow to the spleen is compromised, causing tissue ischemia and eventual necrosis. It may be the result of arterial or venous occlusion. The most commonly associated etiologies are underlying hematologic disorder, blood borne malignancy, blunt abdominal trauma, hypercoagulable state, or embolic illness [14].

Evaluation of patients who present with abdominal pain requires a broad differential approach. Lab evaluation may help rule in/out other causes of abdominal pain. Leukocytosis and elevated lactate dehydrogenase may be found in splenic infarction. Radiographic testing is required to detect this rare illness. In the hyperacute phase of infarction, abdominal CT scan performed with intravenous contrast is the imaging modality of choice in suspected splenic infarction [15]. Treatment of splenic infarct ranges from supportive care to splenectomy.

Dangerous complications of splenic infarction include pseudocyst formation, splenic rupture, and aneurysm. In some instances, the infarcted splenic tissue may become infected and lead to abscess formation. Infarcted tissue may also undergo a hemorrhagic transformation. These complications warrant emergent surgical consultation [16].In our case, the patient did not develop any of these issues, so she was treated conservatively with no surgical intervention.

\section{Conclusion}

The cases of thromboembolism of the abdominal viscera including the spleen as a result of COVID-19 infection are increasing. Hence, it is important to suspect ab- dominal visceral infarction in the COVID-19 patient presenting with acute abdominal pain despite the absence of respiratory symptoms. Imaging to confirm the diagnosis and blood tests to exclude other hematological causes of thromboembolism should be done. A prophylactic dose of low-molecular-weight heparin should be considered to reduce the risk of VTE in those who have COVID-19.

\section{Statement of Ethics}

Written informed consent was obtained from the patient for publication of this case report and any accompanied images. Ethical approval is not required according to DHA committee policies.

\section{Conflict of Interest Statement}

The authors have no conflicts of interest to declare.

\section{Funding Sources}

The authors did not receive any funding.

\section{Author Contributions}

B.J.A. and S.S. both wrote the manuscript. L.S.O. corrected the draft of the manuscript and reviewed the final report.

\section{Data Availability Statement}

All data generated or analyzed during this case report are included in this article. Further inquiries can be directed to the corresponding author.

\section{References}

1 Zhou F, Yu T, Du R, Fan G, Liu Y, Liu Z, et al. Clinical course and risk factors for mortality of adult inpatients with COVID-19 in Wuhan, China: a retrospective cohort study. Lancet. 2020 Mar 28;395(10229):1054-62.

$2 \mathrm{Wu} \mathrm{Z,} \mathrm{McGoogan} \mathrm{JM.} \mathrm{Characteristics} \mathrm{of} \mathrm{and}$ important lessons from the coronavirus disease 2019 (COVID-19) outbreak in China: summary of a report of 72314 cases from the Chinese Center for Disease Control and Prevention. JAMA. 2020 Apr 7;323(13):1239-42.

3 Cui S, Chen S, Li X, Liu S, Wang F. Prevalence of venous thromboembolism in patients with severe novel coronavirus pneumonia. J Thromb Haemost. 2020;18(6):1421-4.
4 Qasim Agha O, Berryman R. Acute splenic artery thrombosis and infarction associated with COVID-19 disease. Case Rep Crit Care. 2020;2020:8880143.

5 Bikdeli B, Madhavan MV, Jimenez D, Chuich T, Dreyfus I, Driggin E, et al. COVID-19 and thrombotic or thromboembolic disease: implications for prevention, antithrombotic therapy, and follow-up: JACC state-of-the-art review. J Am Coll Cardiol. 2020;75(23):295073.
6 Driggin E, Madhavan MV, Bikdeli B, Chuich T, Laracy J, Biondi-Zoccai G, et al. Cardiovascular considerations for patients, health care workers, and health systems during the COVID-19 pandemic. J Am Coll Cardiol. 2020; 75(18):2352-71.

7 Helms J, Tacquard C, Severac F, Leonard-Lorant I, Ohana M, Delabranche X, et al. High risk of thrombosis in patients with severe SARS-CoV-2 infection: a multicenter prospective cohort study. Intensive Care Med. 2020;46(6):1089-98. 
8 Chi G, Lee JJ, Jamil A, Gunnam V, Najafi H, Memar Montazerin S, et al. Venous thromboembolism among hospitalized patients with COVID-19 undergoing thromboprophylaxis: a systematic review and meta-analysis. J Clin Med. 2020;9(8):2489.

9 Connors JM, Levy JH. COVID-19 and its implications for thrombosis and anticoagulation. Blood. 2020;135(23):2033-40.

10 Thachil J, Tang N, Gando S, Falanga A, Cattaneo M, Levi M, et al. ISTH interim guidance on recognition and management of coagulopathy in COVID-19. J Thromb Haemost. 2020; 18(5):1023-6.
11 COVID-19 and coagulopathy - Hematology. org [Internet]. Hematology.org. [cited 2021 Nov 7]. Available from: https://www.hematology.org/covid-19/covid-19-and-coagulopathy.

12 Araya S, Mamo MA, Tsegay YG, Atlaw A, Aytenew A, Hordofa A, et al. Blood coagulation parameter abnormalities in hospitalized patients with confirmed COVID-19 in Ethiopia. PLoS One. 2021;16(6):e0252939.

13 Castro GRA, Collaço IA, Dal Bosco CLB, Corrêa GG, Dal Bosco GB, Corrêa GL. Splenic infarction as a complication of covid-19 in a patient without respiratory symptoms: a case report and literature review. IDCases. 2021; 24:e01062.
14 Medscape.com [Internet]. Parikh M. Splenic infarct: background, anatomy, pathophysiology [cited 2021 Sep 5]. Available from: https: //emedicine.medscape.com/article/193718overview.

15 Balcar I, Seltzer SE, Davis S, Geller S. CT patterns of splenic infarction: a clinical and experimental study. Radiology. 1984;151(3): 723-9.

16 Chapman J, Helm TA, Kahwaji CI. Splenic infarcts. In. StatPearls. Treasure Island, FL: StatPearls Publishing; 2021. 